\title{
ХАРАКТЕРИСТИКА ДИАБЕТИЧЕСКОЙ НЕЙРОПАТИИ У ДЕТЕЙ
}

\author{
В.В. Туз, О.В. Макина, Н.А. Петрова, Е.А. Ларина, М.М. Батяева \\ ГБУЗ «ЯО Областная детская клиническая больнича», ФГБОУ ЯГМУМЗ РФ, Ярославль
}

\begin{abstract}
АКтУАЛЬНОСТь. Диабетическая полинейропатия (ДПН) - наиболее раннее и частое осложнение сахарного диабета 1 типа, которое оказывает существенное влияние на трудоспособность и социальную активность больных. ДПН развивается на фоне хронической гипергликемии и ассоциирована с патологическими метаболическими изменениями (активация полиолового пути, накопление конечных продуктов гликирования, оксидативный стресс, дислипидемия).
\end{abstract}

ЦЕЛЬ - изучение частоты встречаемости, структуры и факторов риска ДПН у детей и подрОСТКОВ.

МАТЕРИАЛЫ И МЕТОДЫ. Обследовано 44 ребенка с СД1 в возрасте 5-17 лет. Диагностика ДПН проводилась с помощью шкал для скрининга и оценки выраженности симптомов диабетической нейропатии: Мичиганского опросника для скрининга нейропатии, шкалы неврологических симптомов, оценки вибрационной чувствительности, тактильной и болевой стандартными методиками. Статистическая обработка оценивалась методом проверки гипотез о равенстве средних значений двух выборок с помощью коэффициента Стьюдента.

РЕЗУЛЬТАТЫ И ОБСУЖДЕНИЕ. ПрИ НеврологИческом осмотре У 31,8\% детей отмечено снижение вибрационной чувствительности, у 20,5\% тактильной. Снижения температурной и болевой чувствительности, нарушения суставно-мышечного чувства выявлено не было. Клинические признаки были оценены нами по совокупности жалоб, их длительности, прогрессирования симптоматики с течением заболевания, а также исходя из снижения чувствительности и рефлексов нижних конечностей. Диагноз ДПН был выставлен $41 \%$ пациентам. Корреляционный анализ показал достоверную связь наличия ДПН с длительностью диабета $(p<0,0005)$, уровнем $\mathrm{HbA}_{1 c}(p<0,05)$. Взаимосвязи с возрастом пациентов, показателями липидного спектра в нашей выборке оказались статистически незначимыми. Диагностика кардиоваскулярной формы проводилась по результатам сбора жалоб пациентов: на приступы сердцебиения без особого напряжения - 9,1\%, на головокружение $-20,5 \%$, на головокружение при резкой смене положения тела - 15,9\%. Жалобы гастроинтестинального характера на боли в животе предъявляли 18,2\% пациентов, на ощущение переполнения желудка $-27,3 \%$, на тяжесть и боль в правом подреберье $-6,8 \%$, на тошноту $-11,4 \%$. Подобные жалобы неспецифичны, но данный факт ставит вопрос о включении таких пациентов в группу риска по гастроинтестинальной нейропатии. Диагностически значимым исследованием мочеполовой нейропатии является урофлоуметрия. С помощью данного метода возможно своевременно определить начальную стадию нарушений мочеиспускания при СД и предотвратить их дальнейшее развитие.

\section{выводы.}

1. Частота встречаемости ДПН составила $41 \%$ с преобладанием начальных клинических форм.

2. Достоверными факторами риска развития ДПН является длительность заболевания 4 года и более, декомпенсированные показатели $\mathrm{HbA}_{1 c}$.

3. Нарушение вибрационной чувствительности выявлено у $31,8 \%$.

4. Пациентов со специфическими жалобами или симптомами необходимо определить в группы риска по формированию диабетической автономной нейропатии. 